
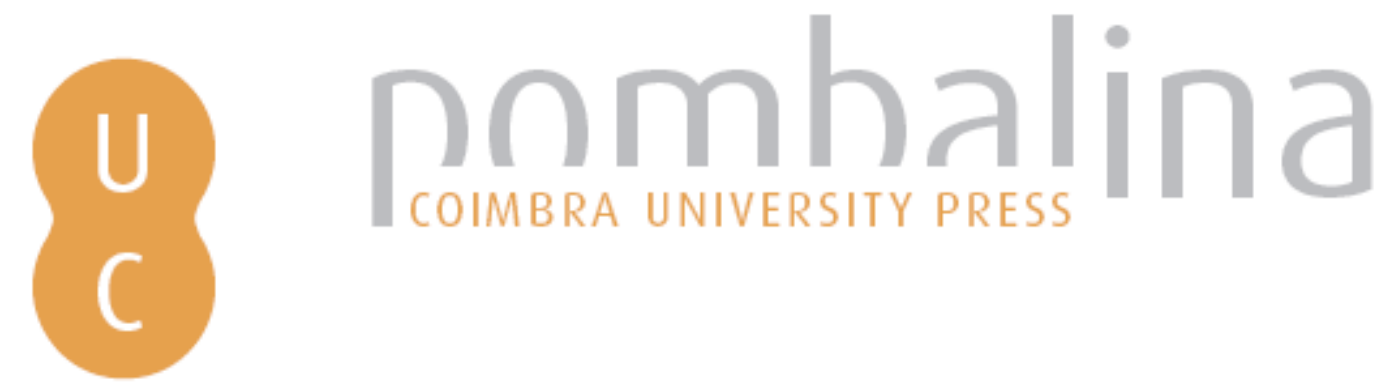

\title{
Formação de Jovens Rurais e Educação Popular: fortalecimento da agricultura camponesa na perspectiva freireana no nordeste brasileiro
}

\author{
Autor(es): $\quad$ Souza, José Ribamar Furtado de; Furtado, Eliane Dayse Pontes \\ Publicado por: Imprensa da Universidade de Coimbra \\ URL \\ persistente: URI:http://hdl.handle.net/10316.2/41305 \\ DOI: $\quad$ DOI:https://doi.org/10.14195/978 $\quad$ 289 26 1326-0_16 \\ Accessed : $\quad$ 26-Apr-2023 16:30:57
}

A navegação consulta e descarregamento dos títulos inseridos nas Bibliotecas Digitais UC Digitalis, UC Pombalina e UC Impactum, pressupõem a aceitação plena e sem reservas dos Termos e Condições de Uso destas Bibliotecas Digitais, disponíveis em https://digitalis.uc.pt/pt-pt/termos.

Conforme exposto nos referidos Termos e Condições de Uso, o descarregamento de títulos de acesso restrito requer uma licença válida de autorização devendo o utilizador aceder ao(s) documento(s) a partir de um endereço de IP da instituição detentora da supramencionada licença.

Ao utilizador é apenas permitido o descarregamento para uso pessoal, pelo que o emprego do(s) título(s) descarregado(s) para outro fim, designadamente comercial, carece de autorização do respetivo autor ou editor da obra.

Na medida em que todas as obras da UC Digitalis se encontram protegidas pelo Código do Direito de Autor e Direitos Conexos e demais legislação aplicável, toda a cópia, parcial ou total, deste documento, nos casos em que é legalmente admitida, deverá conter ou fazer-se acompanhar por este aviso.

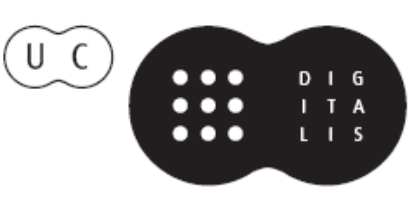




\title{
1 6. FORMAÇÃO DE JOVENS RURAIS E EDUCAÇÃO POPULAR: FORTALECIMENTO DA A GRICULTURA CAMPONESA NA PERSPECTIVA FREIREA NA NO NORDESTE B RASILEIRO
}

\author{
José Ribamar Furtado de Souza 70 \\ Eliane Dayse Pontes Furtado ${ }^{71}$
}

\begin{abstract}
Resumo
O texto aborda a experiência de formação de jovens rurais desenvolvida no Estado do Ceará, Brasil, através da parceria estabelecida entre a Secretaria Nacional da Juventude da Secretaria Geral da Presidência da República (SNJ/SG-PR) e as Universidades de Brasília (UNB) e Internacional da Lusofonia Afro-Brasileira (UNILAB). A "Formação de Jovens Rurais para o Fortalecimento da Agricultura Camponesa no Semiárido Cearense", como assim foi designado o curso, envolveu um total de 300 jovens, que participaram nas 300 horas de atividades planejadas.
\end{abstract}

70 Professor Colaborador do Programa de Pós-Graduação em Educação Brasileira da Faculdade de Educação da Universidade Federal do Ceará. Professor Visitante da Universidade da Integração da Lusofonia Afro-Brasileira-UNILAB Rural (UNILAB). Pós-Doutorado London School of Economics and Political Sciences - University of London

${ }^{71}$ Professora Titular do Departamento de Estudos Especializados da Faculdade de Educação (FACED), da Universidade Federal do Ceará (UFC);Professora e pesquisadora do Programa de Pós-graduação em Educação Brasileira da FACED/ UFC;Pós-doutorado como professora visitante no Instituto de Educação de Londres 
A formação seguiu uma abordagem de Intervenção Participativa de Atores, demonstrando uma metodologia baseada em princípios freireanos de uma Educação Libertadora. A metodologia contou também com a estratégia de Formação por Pares, em que jovens mais experientes, lideranças rurais e com nível de escolarização superior, atuaram, após participarem de um período prévio de formação de formadores, como facilitadores do processo de formação de outros jovens. O curso foi organizado em três módulos construídos sobre temáticas centrais no processo formativo de jovens do campo: formação cidadã e participação social, trabalho e geração de renda e elaboração de projetos. Esses módulos foram desenvolvidos a partir de princípios da Pedagogia da Alternância, em que, após cada segmento teórico, havia lugar para um segmento de prática de campo. Entre as lições da prática, conclui-se que a conjugação de metodologias adotadas permitiu aos sujeitos uma análise dos conhecimentos sobre si, sobre as suas condições de vida e, nesse âmbito, levantar dados para melhor conhecer a sua realidade, planejar ações nesses territórios e agir de forma consciente para transformar a realidade em que vivem.

\section{Abstract}

This text addresses an educative experience with young people from rural areas in Ceará-Brazil. This experience was developed through a partnership between the Secretaria Nacional da Juventude da Secretaria Geral da Presidência da República (SNJ/ SG-PR - National Secretary of Youth of the General Secretary of Republic Presidency), the Universidade de Brasília (UNB University of Brasília) and the Universidade Internacional da Lusofonia Afro-Brasileira (UNILAB - International University of the Afro-Brazilian Portuguese-speaking). The "Training of 
Youngsters from Rural Areas to the Strengthening of the Peasant Agriculture", as it was called the course, involved 300 students in the 300 hours of the planned activities. The training followed a Participatory Intervention approach, highlighting a methodology based on Freire's principles of Liberating Education. The methodology also included the strategy of Peer Training, in which more experienced young individuals, rural leaders and with high level of education, after take part in a previous course of training of trainers, acted as facilitators in the training process of other young individuals. The course was built into three modules which addressed central themes to the training process of the youngsters: citizenship education \& social participation, employment, and income generation \& projects of development. These modules were developed from principles of Pedagogy of Alternation: after each theoretical segment there was place for a field practice. Among the lessons of the practice, it is possible to conclude that the conjugation of the methodologies applied enabled individuals to analyze themselves and their life conditions. Within this context, they were able to better understand their reality, to plan actions and to act consciously to change such reality. 


\section{Introdução}

Este trabalho trata de uma experiência de formação de jovens rurais com uma abordagem participativa baseada na Intervenção Participativa dos Atores (INPA) (Furtado \& Furtado de Souza, 2000), utilizando uma metodologia que foi sendo gradativamente construída em três campos principais: Educação Popular, Educação de Jovens e Adultos e Educação do Campo, com base nos princípios freireanos de Educação Libertadora, por uma equipe de professores da universidade, que tem nos autores deste texto seus principais coordenadores. Ainda, a Pedagogia da Alternância deu o norte das ações concretas do curso.

A proposta pedagógica da INPA implica um processo educativo no qual cada um, individualmente, e todos, no coletivo, tenham clara a sua posição de sujeitos da história, ou seja, de que podem mudar sua realidade. Baseia-se na concepção de capacitação formativa, reflexiva, interativa e continuada, na busca de pessoas, lideranças locais e de um profissional, um jovem, "comprometido com a sociedade". Ofereceu uma variedade de técnicas educativas, dinâmicas de grupo, atividades concretas para obter informações sobre ideias relevantes ou fatos da realidade de vida dos jovens, organizá-los e interpretá-los e, a partir daí, planejar ações para a transformação.

O Curso de Formação Cidadã e Agroecológica para o fortalecimento da Inclusão Produtiva da Juventude Rural foi uma promoção da Secretaria Nacional de Juventude da Secretaria geral da Presidência da República (SNJ/SG-PR) do Brasil, que estabeleceu parcerias com a Universidade de Brasília (UNB) e a Universidade Internacional da Lusofonia Afro-brasileira (UNILAB) para sua realização, com carga horária total de 300 horas-aula, para 300 jovens do meio rural de cada uma das unidades (Distrito Federal e estado do Ceará). Fez parte do Programa Nacional de Inclusão Produtiva da Juventude Rural com Formação Cidadã e Agroecológica e visava 
dar respostas concretas à realidade da juventude rural e às demandas específicas dessa juventude e dos movimentos sociais. No Ceará, o curso recebeu o título de FORMAÇÃO DE JOVENS RURAIS PARA O FORTALECIMENTO DA AGRICULTURA CAMPONESA NO SEMIÁRIDO CEARENSE [ênfase adicionada], e teve uma conotação própria de ter se baseado na perspectiva freireana da educação libertária. As palavras de Freire (2014) nesta passagem fundamentam a opção pela abordagem:

Se os seres humanos fossem puramente determinados e não seres "programados para aprender", não haveria por que, na prática educativa, apelarmos para a capacidade crítica do educando. Não havia por que falar em educação para a decisão, para a libertação. Mas, por outro lado, não havia também por que pensar nos educadores e nas educadoras como sujeitos. Não seriam sujeitos, nem educadores, nem educandos, como não posso considerar Jim e Andra, meu casal de cães pastores-alemães, sujeitos da prática em que adestram seus filhotes, nem a seus filhotes objetos daquela prática. Lhes faltam a decisão, a faculdade de, em face de modelos, romper com um, optar por outro (Freire, 2014, pp. 16-17).

O contexto de surgimento do curso deu-se no ano de 2011, quando a juventude rural organizada em diferentes movimentos sociais apresentou suas demandas em diversos ministérios e na Secretaria Nacional de Juventude (SNJ). A principal preocupação da juventude era a ausência de uma política integrada que atendesse às suas necessidades mais imediatas e que promovesse mudanças significativas no meio rural e na floresta. Mostravam-se os jovens estarem comprometidos com a construção de um projeto de desenvolvimento para o país que garantisse sua inclusão social, econômica e cultural. De fato, as políticas públicas relacionadas a esse importante segmento da população ainda são dispersas e "não 
respondem a uma situação perversa que gera exclusão do jovem e da jovem do campo brasileiro" (TR UNB, 2012, p.1).

Segundo o Instituto Brasileiro de Geografia e Estatística IBGE, "dos 50 milhões de jovens brasileiros, aproximadamente 8 milhões, entre 15 a 29 vivem no campo, isto é, $15,1 \%$ dos jovens no Brasil e nesse grupo estão situados $29,5 \%$ dos jovens pobres do país". Há ainda um agravante: os casos de trabalho análogo à escravidão que são encontrados no cenário rural brasileiro. De acordo com os dados da Comissão Pastoral da Terra, em $2011^{72}$ foram registrados 214 casos de trabalho análogo a escravidão. Esse contexto associado à persistência da cultura patriarcal que exclui os jovens e as jovens dos espaços de decisão tem sido responsável pela migração para as cidades de médio e grande porte. Essa condição de desvantagem em que se encontra a juventude do campo, gerando o problema da sucessão rural, faz surgir políticas que buscam garantir a consolidação da agricultura familiar, fortalecendo a agroecologia, "na busca de uma produção agropecuária e de alimentos em bases ecológicas com a conservação dos recursos naturais no Brasil" (TR UNB, 2012).

No Ceará, o curso de formação de jovens rurais compreendeu 12 municípios do estado localizados em três territórios, Sertões de Canindé e dos Inhamuns e Vale do Curu Aracatiaçu. Dentro desses territórios tivemos jovens distribuídos em 37 assentamentos e 36 comunidades, perfazendo um total de 73 unidades. O curso tinha com objetivo,

[...]Oportunizar o aumento das relações sociais e de cidadania; a valorização e conservação dos saberes tradicionais da população do campo de sua região e localidade; a diversificação e potencialização das atividades geradoras de renda, com isso

72 Dados registrados de janeiro a outubro de 2011. 
possibilitando o aproveitamento das potencialidades locais e regionais, fortalecendo o protagonismo juvenil e a emancipação da juventude. (UNILAB TR, 2011)

Apesar de o curso ser voltado para a Agricultura Familiar e Agroecologia, a equipe do projeto, conhecedora da realidade do campo no Ceará, estado nordestino totalmente localizado no perímetro da seca, decidiu adotar uma metodologia de Educação Popular, que tem sua base nos princípios freireanos, a fim de possibilitar conhecimento do contexto e gerar reflexões sobre a realidade. Convidamos como parceiros o Movimento dos trabalhadores sem Terra (MST), a Federação dos Trabalhadores e Trabalhadoras Rurais do Ceará (FETRAECE) e a Pastoral da Juventude Rural (PJR). Isto quer dizer que desde o seu ponto de partida baseou-se no diálogo, no conhecimento da realidade e na participação, porque, como Freire, acreditamos que a educação é um ato político. Em suas palavras...

[...] para mim, a educação é política. Hoje, digo que a educação tem a qualidade de ser política, o que modela o processo de aprendizagem. A educação é política e a política tem educabilidade. (Freire \& Shor, 1986, pp.76-77)

O trabalho tem foco num processo de formação e a estratégia utilizada propõe que os capacitandos passem a conhecer metodologias participativas de planejamento territorial e estejam aptos a elaborar projetos produtivos coletivos, com a participação de todos, na perspectiva do desenvolvimento sustentável.

Este texto trata desse processo e consta das seguintes partes, além desta introdução que apresenta o trabalho e o curso; o segundo item trata do percurso metodológico, onde é apresentada a dinâmica de funcionamento, sua estrutura curricular, os métodos e algumas técnicas utilizadas e, por fim, traz as lições aprendidas 
na prática coletiva com jovens, comunitários, facilitadores e professores universitários.

\section{Percurso metodológico}

O percurso metodológico, inspirado na pedagogia freireana, fundamenta-se nos dizeres de Freire:

O compromisso, próprio da existência humana, só existe no engajamento com a realidade, de cuja "águas" os homens verdadeiramente comprometidos ficam "molhados", ensopados. Somente assim o compromisso é verdadeiro. Ao experienciá-lo, num ato que necessariamente é corajoso, decidido e consciente, os homens já não se dizem neutros (1979, p.19).

O Curso de Formação foi organizado em três módulos perpassados por eixos considerados centrais no processo formativo dos jovens do campo, com participação social, em que os jovens ficavam imersos na sua realidade, porém com outro olhar: o da reflexão sobre suas vidas. Foram desenvolvidos obedecendo a pedagogia da Alternância, isto é, após cada segmento teórico, chamado "tempo-escola", havia um segmento de prática de campo, "tempo-comunidade", onde os alunos iam para as comunidades com atividades programadas e acompanhados por seus professores e facilitadores. Os módulos eram assim denominados: (a) formação cidadã e participação social; (b) coletivos de auto-organização; capacitação para o trabalho e renda; (c) tecnologias de comunicação e informação e elaboração dos projetos coletivos de geração de renda. Eles foram desenvolvidos através de eixos centrais, que por sua vez, contemplam os componentes curriculares, levando à formação desejada. 


\begin{tabular}{|c|c|c|c|}
\hline \multirow[b]{2}{*}{ Módulos } & \multirow[b]{2}{*}{ Componentes Curriculares } & \multicolumn{2}{|c|}{ Carga Horária } \\
\hline & & T-Esc & T-Com \\
\hline $\begin{array}{l}\text { Formação } \\
\text { cidadã e } \\
\text { participação } \\
\text { social }\end{array}$ & $\begin{array}{l}\text { Unidade Introdutória - Elementos Fundantes } \\
\text { - } \quad \text { Bases para o processo de construção de saberes e } \\
\text { conhecimentos na perspectiva "Freireana". Os estados } \\
\text { da consciência, direitos e deveres; } \\
\text { - } \quad \text { Noções sobre as TICs; } \\
\text { O contexto nacional e internacional do } \\
\text { desenvolvimento: concepções de desenvolvimento, de } \\
\text { Estado e de Sociedade; } \\
\text { Educação do campo: a pedagogia e os métodos nas } \\
\text { relações sociais (Intervenção Participativa dos Atores- } \\
\text {-INPA e DRP). } \\
\text { Aprendizagem Baseada em Problemas - ABP e } \\
\text { Metodologia da Problematização; } \\
\text { Elementos do Planejamento Estratégico Participativo; }\end{array}$ & 64 & \\
\hline $\begin{array}{l}\text { Trabalho e } \\
\text { geração de } \\
\text { renda }\end{array}$ & $\begin{array}{l}\text { História da Agricultura: modos de produção - } \\
\text { campesinato, agricultura de subsistência, agricultura } \\
\text { patronal e empresarial e agricultura familiar; } \\
\text { A Questão agrária no semiárido: reforma agrária, } \\
\text { movimentos sociais e sindicais, ONGs, partidos } \\
\text { políticos e Igreja; } \\
\text { Agricultura e a natureza: sistemas agrícolas, } \\
\text { ecologia (agriculturas) - cultivo, criação e a floresta. } \\
\text { A ruralidade emergente: a questão campo e cidade, } \\
\text { espaço rural e territórios, multifuncionalidade e } \\
\text { pluriatividade da agricultura, agronegócio/cadeias } \\
\text { produtivas/ complexos agroindustriais, segurança } \\
\text { alimentar e nutricional/soberania alimentar, sócio- } \\
\text {-economia solidária e mercado/comércio justo, } \\
\text { as relações de gênero, geração e etnia, indústria } \\
\text { doméstica rural, ocupação e emprego, migrações } \\
\text { (despovoamento) e imigrações, envelhecimento } \\
\text { e feminilização/masculinização, aposentadoria e } \\
\text { políticas compensatórias; } \\
\text { Políticas públicas no semiárido: novas } \\
\text { institucionalidades, organização social, mobilização, } \\
\text { cooperação (associativismo e cooperativismo), } \\
\text { controle e regulação social; responsabilidade social e } \\
\text { voluntariado, juventude rural, terceiro setor, OSCIPS, } \\
\text { organização social, arranjos produtivos locais, } \\
\text { consórcios, parcerias público-privado, fundo de aval, } \\
\text { condomínios; redes sociais; políticas assistencialistas } \\
\text { (bolsas) aposentadorias, instrumentos e modelos de } \\
\text { gestão para execução das políticas públicas (fóruns, } \\
\text { conselhos, comitês, equipes gestoras, entre outras); }\end{array}$ & 80 & $\begin{array}{c}104 \\
\text { (Autodiagnóstico } \\
\text { I, II e III) }\end{array}$ \\
\hline $\begin{array}{l}\text { III-Elaboração } \\
\text { de Projetos }\end{array}$ & $\begin{array}{ll}\text { - } & \text { Troca de Saberes - dialogando com os pares; } \\
\text { - } & \text { Formação de formadores jovens para os novos cursos; } \\
\text { Apresentação das Agendas de Prioridades (projetos } \\
\text { e ações), com seu modelo de autogestão (espaço } \\
\text { consultivo, deliberativo e executivo). }\end{array}$ & 24 & $\begin{array}{c}28 \\
\text { (Agendas } \\
\text { de Prioridades) }\end{array}$ \\
\hline Total & & 168 & 132 \\
\hline
\end{tabular}


O Projeto foi executado através de dois blocos de cinco turmas, com trinta jovens cada uma, perfazendo um total de 300 participantes, em sete semanas e meia, com 168 horas de Tempo-Escola e 132 horas de Tempo-Comunidade, perfazendo 300 horas. Cada bloco consistiu de quatro encontros presenciais, Tempo-Escola, de cinco dias letivos ou 40 horas semanais e um encontro final de oito horas, num total de 168 horas. Por sua vez foram 04 encontros no campo, Tempo-Comunidade, sendo dois de cinco dias letivos ou 80 horas, um de três dias e meio ou 28 horas e um de três dias ou 24 horas, num total de 132 horas.

Antes do início do curso, propriamente dito, com a presença dos jovens rurais, foi realizada a formação dos formadores. Isto porque adotamos a técnica da Formação por Pares, inspirada na estratégia de atuação comunitária, "Peer Etnographic Tool" desenvolvida pelo Centro de Estudos do Desenvolvimento, da Universidade de Swansea, no País de Gales (Howkins \& Price, 2000), desenvolvida em trabalhos de pesquisa na área de saúde. A metodologia caracteriza-se como uma ferramenta que possibilita um processo de diálogo entre a comunidade, os formuladores de políticas e os gerentes de programas de desenvolvimento. Desse ponto partimos para uma construção coletiva, em relação à formação de profissionais do campo. Assim, ela foi chamada de Metodologia de "Formação por Pares" onde as pessoas são formadas, também, por seus próprios pares, o que possibilita uma aproximação real das experiências, práticas e vivências de campo, das políticas, programas e projetos em andamento, bem como das questões institucionais vividas pelos participantes, propiciando momentos ricos de reflexão das mesmas. Isso também possibilita um maior compromisso com a realidade que aos poucos vai se descortinando. Como diz Freire (1979): "O verdadeiro compromisso é a solidariedade, e não a solidariedade com os que negam o compromisso solidário, mas com aqueles que, na situação concreta, se encontram convertidos em "coisas". Comprometer-se com a desumanização é assumi-la e, inexoravelmente, desumanizar-se também" (p.19). 
Adaptada a metodologia a fim de garantir a qualidade da formação com participação, uma etapa preliminar se fez necessária, para selecionar e mobilizar os facilitadores. Ela consistiu em selecionar jovens rurais mais experientes, ainda dentro da faixa etária, até 29 anos, lideranças rurais e com um nível de escolarização superior, para atuarem como facilitadores do processo de formação dos jovens. Foram formados quinze (15) jovens para atuar em todas as etapas da formação, em grupos de três para cada grupo de 30 jovens. Uma vez selecionados foi feita uma revisão bibliográfica e levantamento de dados secundários das regiões a serem trabalhadas, posteriormente, socializados nos "ambientes de reflexão". Ainda, nestes, foram elaboradas as fichas pedagógicas para o desenvolvimento das atividades, com o detalhamento da temática em foco, que cada momento no ambiente de problematização exigia.

Os encontros presenciais do Tempo-Escola tiveram início com o "Fórum de escuta' que se apoia na concepção de que ao se iniciar um trabalho com comunidade ou grupos sociais, o primeiro passo é sensibilizá-los, fazendo-os refletir sobre sua realidade, anseios e aspirações, problematizando, a partir daí, para iniciar uma construção coletiva que permita o desenvolvimento do trabalho que se pretende realizar, buscando aproximar-se, o máximo possível da sua realidade. Em suma, consiste em colocar em interação o conhecimento "nativo" - Indigenous Knowledge e o conhecimento científico levado pelos professores e facilitadores, possibilitando teorizar sobre a prática. Concretamente consiste em ouvir os participantes, em grupos específicos e em plenária, e fazer discussões utilizando mapas, croquis e dinâmicas de grupo e materiais que os estimulavam a refletir e a falar, porque é muito comum, que:

[...] de tanto ouvirem de si mesmos que são incapazes, que não sabem nada, que não podem saber, que são enfermos, indolentes, que não produzem em virtude de tudo isto, terminam por 
se convencer de sua "incapacidade". Falam de si como os que não sabem e do "doutor" como o que sabe e a quem devem escutar [...]. Dentro dos marcos concretos em que se fazem duais é natural que descreiam de si mesmos. (Freire, 1987, p.50).

E, ao mesmo tempo que se trabalhava esta questão era importante fazer a preparação para o autodiagnóstico, a etapa seguinte.

No primeiro encontro do "tempo-escola", foi trabalhada uma mística que tratava da realidade brasileira, representada por jovens, do Movimento dos Sem Terra (MST) e outros, do próprio curso. Os encontros, no início da manhã, davam-se num auditório, chamado de "ambiente de troca de saberes", ou seja, ambiente de problematização dos conteúdos, onde os professores da universidade realizavam uma palestra interativa sobre o conteúdo do dia, usando diferentes recursos. Em seguida, dirigiam-se aos "ambiente de reflexão", para onde se dirigia cada turma ${ }^{73}$ para dar continuidade às atividades do dia. Os facilitadores eram responsáveis pelas atividades, desenvolvidas aí, sempre acompanhados pelos coordenadores do curso. Com as mais variadas estratégias, planejadas coletivamente e rigorosamente selecionadas para garantir o encadeamento do assunto tratado, buscavam provocar nos jovens desinibição e reflexões. Como exemplo vale citar um quebra-cabeça gigante que deveria ser montado por eles, espontaneamente, enquanto o grupo de facilitadores acompanhava a dinâmica do grupo para realização da atividade. Faziam anotações e fotografavam. Ao findar a atividade seguiam-se os comentários, quando os jovens falavam da experiência, o que representou para eles, o que evocou e o que

73 Para formação das turmas foram utilizados os critérios de proximidade de moradias dos jovens e a faixa etária. Tentou-se agrupá-los pensando no tempo comunidade, o máximo possível, numa comunidade/assentamento ou em comunidades/assentamentos próximos. Exceção para as comunidades de Pescadores, que tiveram turma específica. 
quisessem comentar. Muitas outras atividades foram desenvolvidas com o mesmo objetivo de conhecer a realidade, tendo, inclusive, sido desenvolvida uma pesquisa, ao mesmo tempo, que incluiu a aplicação de um questionário de perfil e realizados sete (7) grupos focais. As atividades tinham um direcionamento de mergulhar na realidade para melhor conhecê-la e atuar sobre ela, que se justifica nos dizeres de Freire:

[...] o nosso mover-nos nele [no mundo] e na história vem envolvendo necessariamente sonhos por cuja realização nos batemos. Daí então, que a nossa presença no mundo, implicando escolha e decisão, não seja uma presença neutra. A capacidade de observar, de comparar, de avaliar para, decidindo, escolher, com o que, intervindo na vida da cidade, exercemos nossa cidadania, se erige então como uma competência fundamental. Se a minha não é uma presença neutra na história, devo assumir tão criticamente quanto possível sua politicidade. Se, na verdade, não estou no mundo para simplesmente a ele me adaptar, mas para transformá-lo; se não é possível mudá-lo sem um certo sonho ou projeto de mundo, devo usar toda possibilidade que tenha para não apenas falar de minha utopia, mas para participar de práticas com ela coerentes (2000, p. 33).

Concluído o período de diagnóstico no tempo escola, o fórum de escuta, foi desenvolvido o primeiro tempo-comunidade cujas atividades consistiam de contatos com os técnicos e as lideranças locais e, ainda, as visitas domiciliares; reuniões de sensibilização em que foram provocadas discussões, através de metodologias participativas, em preparação para o autodiagnóstico coletivo, o que provocou uma mobilização geral para a realização de um planejamento participativo, também inspiradas na perspectiva freireana. Isso significa dizer que a ideia de ação-reflexão-ação havia perpassado todas as ações. Para Freire (1987. p, 50) "o ato de conhecer envolve um movimento 
dialético que vai da ação à reflexão sobre ela" e, desta, para uma nova ação. E completa ainda: "só existe saber na invenção, na reinvenção, na busca inquieta, impaciente, permanente que os homens fazem no mundo, com o mundo e com os outros" (Freire 1987, p.58).

Como exemplo desse movimento é possível citar que para o levantamento dos problemas das comunidades foram formadas comissões temáticas de saúde, educação, infra-estrutura, produção, lazer e cultura. As comissões eram compostas pelos jovens, um (1) facilitador e pessoas da comunidade que se reuniam para planejar e realizar uma pesquisa na comunidade sobre estes diferentes temas. Os comunitários eram questionados sobre suas potencialidades e dificuldades, na sua totalidade. Daí seguia um processo de sistematização em grupo, e novos questionamentos, até chegar aos problemas que precisavam ser enfrentados, priorizando-os e buscando resolvê-los através de ações ou de projetos. Enquanto isso as pessoas vão se empoderando por meio do conhecimento da sua própria realidade. Como diria Freire, quando fala da pedagogia do oprimido: "os oprimidos vão desvelando o mundo da opressão e vão comprometendo-se, na práxis, com a sua transformação”(1987, p.41).

Assim, esta primeira alternância consistiu em atividades de campo, nos próprios locais onde vivem os jovens, suas comunidades ou assentamentos rurais; novas reuniões para reflexão da realidade a fim de atender as demandas concretas do campo. Por questões orçamentárias os 300 (trezentos) jovens cursistas realizam o trabalho de campo (Tempo-Comunidade) em apenas 12 (doze) unidades, 08 assentamentos e 04 comunidades,

Os Tempos-Comunidade envolveram diretamente, 941 famílias. Admitindo-se que a média de pessoas por família que vive no campo gira em torno de 05 pessoas, temos o envolvimento de 4.705 pessoas. Ainda, considerando que a maioria dos jovens não vive nas unidades onde se realizam o Tempo-Comunidade, tem-se um envolvimento 
indireto de 1.824 famílias ou 9.120 (nove mil cento e vinte), pessoas, considerando a média anterior de pessoas por família. Somando-se às pessoas envolvidas diretamente, há uma participação total de 13.825 (treze mil oitocentos e vinte e cinco), pessoas, nos três territórios já citados (Furtado de Souza \& Outros, 2014).

Organizados em grupos, os jovens e os assentados e as assentadas, os agricultores e as agricultoras locais, conforme haviam definido na primeira etapa da pesquisa diagnóstica, continuaram se encontrando e discutindo os problemas, as potencialidades, as soluções, as ações e projetos a serem encaminhados, nas etapas seguintes do autodiagnóstico. A partir dos resultados foram feitos alguns ajustes nos componentes curriculares, conforme a necessidade. Fica, dessa forma, caracterizada a gestão coletiva do desenvolvimento que vai se aprimorando, à medida que todos vão amadurecendo nesse processo. Novas formas de gestão vão sendo criadas, novos grupos formados e uma dinâmica participativa e autônoma se instala. Os técnicos que dão assistência local, envolvidos, por sua vez, vão aos poucos mudando sua postura assistencialista para uma postura cooperativa e reflexiva.

O segundo e terceiro tempo-escola foram estruturados para viabilizar a participação, o debate, o diálogo e a crítica, num processo de sensibilização e construção coletiva, onde formadores e formandos eram sujeitos do processo. Numa sequência de estudos diários, que parte de uma sensibilização e motivação iniciais sobre os temas da capacitação, o conteúdo programático foi desenvolvido através de didáticas e técnicas de ensino as mais diversas. O segundo tempo escola iniciou com o teatro sobre o livro Suzana e o Mundo do dinheiro que funcionou como motivação para essa leitura e para muitas outras atividades do módulo. O "jogo das agriculturas”, por exemplo, preparou o grupo para pensar no agronegócio e na agricultura familiar. E, assim, vai aos poucos se ampliando 
a capacidade de compreender as desigualdades, tanto por parte dos jovens quanto por parte dos comunitários. No segundo tempo comunidade foram iniciadas as práticas agrícolas na perspectiva da agroecologia, sempre refletindo em campo o que havia sido trabalhado nos ambiente de troca de saberes e de reflexão.

Continua então o ciclo, passado o tempo-escola, a próxima atividade de alternância inicia-se. No decorrer de todas as semanas do tempo-escola, diariamente era feita, por uma dupla, a memória do dia anterior, bem como uma avaliação, utilizando diferentes técnicas mas garantindo o registro escrito. Os jovens participantes das oficinas viveram, em campo, a abordagem trabalhada nas reflexões teóricas e, da mesma forma, através de dinâmicas grupais, filmes, mensagens de reflexão dão continuidade ao diagnóstico com as comunidades, divididos em equipes de 6 ou 8 jovens que juntos com os agricultores iam questionando-os e provocando-os para refletirem sua ação e pensarem numa ação renovada.

Conhecer sua própria realidade, de forma crítica, foi o mais importante. E, assim, através de desenhos, mapas da comunidade, da produção, das atividades laborais, de grupos de discussão, de dinâmicas participativas, foram aos poucos construindo suas Agendas de Prioridades. Estas, com seus projetos produtivos agrícolas e não agrícolas, levaram a um modelo de autogestão e a um espaço com papéis consultivo, deliberativo e executivo.

\section{Atividades desenvolvidas por etapa}

\begin{tabular}{|l|l|}
\hline ETAPA & ATIVIDADE \\
\hline \multirow{2}{*}{ I. Preliminar } & 1. Seleção e mobilização dos Facilitadores. \\
\hline \multirow{3}{*}{$\begin{array}{l}\text { II. Preparatória para o } \\
\text { trabalho }\end{array}$} & $\begin{array}{l}\text { 2. Revisão bibliográfica e levantamento dos dados } \\
\text { secundários das regiões a serem trabalhadas. }\end{array}$ \\
\cline { 2 - 2 } & 3. Formação dos Facilitadores. \\
\cline { 2 - 2 } & 4. Elaboração das fichas pedagógicas. \\
\hline
\end{tabular}




\begin{tabular}{|c|c|}
\hline \multirow{4}{*}{$\begin{array}{l}\text { III. Aproximação inicial com } \\
\text { o público }\end{array}$} & 5. Contatos com técnicos locais \\
\hline & 6. Visitas domiciliares \\
\hline & 7. Fórum de Escuta \\
\hline & 8. Preparação para o Autodiagnóstico \\
\hline \multirow{10}{*}{$\begin{array}{l}\text { IV - Momentos de } \\
\text { Alternância } \\
\text { Tempo-Comunidade/Tempo- } \\
\text {-Escola }\end{array}$} & 9. Autodiagnóstico I \\
\hline & 10. Ajustes nos componentes curriculares \\
\hline & $\begin{array}{l}\text { 11. Módulo I - Formação em Cidadania e Participação } \\
\text { Social }\end{array}$ \\
\hline & 12. Autodiagnóstico II \\
\hline & 13.Módulo II - Trabalho e Geração de Renda \\
\hline & 14. Autodiagnóstico III \\
\hline & 15. Módulo III - Elaboração de Projetos \\
\hline & 16. I Oficina: Construção das Agendas de Prioridades \\
\hline & $\begin{array}{l}\text { 17. II Oficina: Consolidação das Agendas de } \\
\text { Prioridades com espaço consultivo, deliberativo e } \\
\text { executivo - modelo de autogestão - e formação dos } \\
\text { grupos de jovens animadores ("multiplicadores") }\end{array}$ \\
\hline & 18. Encerramento \\
\hline \multirow[b]{2}{*}{ V - Elaboração de documentos } & 19 Agenda de Prioridades com modelo de gestão \\
\hline & 20. Sistematização e avaliação da experiência piloto \\
\hline \multirow[b]{2}{*}{ VI - Registro da experiência } & 21. Produção de DVD \\
\hline & $\begin{array}{l}\text { 22. Texto relatando a experiência - artigo científico e/ } \\
\text { ou livro. }\end{array}$ \\
\hline
\end{tabular}

Quanto à avaliação, ela ocorreu de forma processual. Os professores com a participação dos facilitadores realizam reuniões de avaliação diárias e, ainda, uma avaliação de meio termo e uma ao final das oficinas. Além disso, a fase de Alternância, em campo, também envolveu reflexões diárias com os jovens em formação e com os facilitadores.

\section{Lições da prática}

Tendo realizado essa experiência de ida e vinda, na troca de conhecimento e saberes, num grupo heterogêneo, de fato, pois além dos jovens, os sujeitos imediatos, os comunitários que foram também incluídos, numa troca permanente, a conclusão é de que todo o grupo cresceu como educadores e educandos, a despeito 
da complexidade da tarefa. Esta foi árdua, difícil de concretizar-se, mas exercitando a "paciência pedagógica" passo a passo, a "escuta dos sujeitos", ao longo do conhecimento concreto da realidade, da cultura dos comunitários, de seus modos de fazer e viver, em atos de reflexão, na perspectiva da transformação de uma realidade dura de se viver, fica o sentimento de realização.

A missão construída num processo participativo de ação-reflexão-ação revelou que tal processo formativo está relacionado à produção do conhecimento teórico sobre a realidade, gerando a assunção gradual de responsabilidade coletiva, além de promover iniciativas desafiadoras quanto às relações de poder. Freire acreditava que estas relações eram sempre relações pedagógicas e políticas. De fato, ao ouvir e observar a realidade dos jovens rurais e suas famílias, o grupo ia, gradativamente, buscando um chão para suas ações que não podia ser outro senão o que se vivia junto com eles. Notava-se claramente a diferença quando uma atividade era proposta a partir da realidade deles, da compreensão de mundo que eles tinham, tendo-se que recuar muitas vezes para poder dar um salto maior.

A prática do assistencialismo, arraigada no nordeste brasileiro transforma os agricultores em seres passivos, sem possibilidades de participar de um processo que propõe junto com eles promover uma transformação da sua própria realidade. E, com os jovens não podia ser diferente. O silêncio e a passividade iniciais foram aos poucos, através das atividades práticas, dialógicas, da participação, transformando-se no exercício da responsabilidade, em relações solidárias, no exercício da curiosidade e da evolução para uma consciência crítica. Uma educação libertadora conduz a relações democráticas, à solidariedade, a um processo educativo democrático.

Da parte dos jovens era visível seu comprometimento gradativo com o trabalho, à medida que as ações foram avançando com as idas a campo e a parte prática foi dando sentido ao que estudavam em sala de aula. Eles começaram a construir laços de solidariedade e 
compromisso e a se revelar. Antes eles pouco falavam das atividades que faziam no assentamento, parecendo que tinham vergonha de falar sobre elas, pois a meta da maioria era estudar para sair da roça. Á medida que seu espírito crítico ia evoluindo, iam tomando consciência crítica da realidade e alternativas iam sendo apontadas ou descobertas, eles foram mudando sua visão e se envolvendo cada vez mais nas atividades propostas. Na culminância do trabalho foi feito um Acampamento Pedagógico nos dois municípios, Crateús e Canindé, para apresentação de todas as atividades do curso pelas equipes e foi gratificante ver o envolvimento deles e a propriedade como falavam para os dirigentes municipais, presidentes de associações, movimentos sociais, sindicatos e o público do município, presentes à atividade.

Ao mesmo tempo em que a universidade respondia ao direito da população do campo à educação, era oferecida uma educação enraizada no local em que vivem os jovens rurais, com a participação das comunidades envolvidas, onde foi gerado um processo de formação de sujeitos, capazes de participação política na construção do projeto histórico da sociedade brasileira. E, ainda, o eixo do desenvolvimento rural foi trabalhado explicitando os modelos de desenvolvimento em disputa no campo brasileiro e destacando a importância da Agricultura Familiar e de uma relação orgânica entre campo e cidade, para a superação das desigualdades econômicas, sociais e educacionais.

A metodologia de Formação por Pares permitiu que os jovens tivessem contato direto com outros jovens do campo, já mais experientes e, com eles, também aprendessem. E, para estes, a relação com os mais jovens foi enriquecedora, pois os fizeram construir estratégias de diálogo e de construção de novos conhecimentos. A Pedagogia da Alternância foi responsável pela dinâmica de desenvolvimento do curso pois ela permitiu que as atividades fossem realizadas tanto em sala de aula - tempo escola - como no campo - tempo comunidade, possibilitando a efetivação de reflexões que iam e vinham da sala de aula para o campo. 
A conjugação das metodologias adotadas permitiu aos sujeitos locais analisar seus conhecimentos sobre si, sobre suas condições de vida, levantar dados para conhecer melhor sua realidade, elaborar o planejamento de ação dos seus territórios e agir de forma consciente para transformar a realidade em que vivem. Tudo isso feito em conjunto com os profissionais que atuam nas comunidades, e suas lideranças, que também refletem sobre sua prática.

Com a utilização de dinâmicas grupais, vídeos, músicas e produção coletiva os jovens e comunitários foram aos poucos realizando uma radiografia dos locais, com o fim de elaborarem uma Agenda de Prioridades a partir dos problemas, potencialidades e possíveis soluções discutidas coletivamente. Elas serviram de respaldo às comunidades na execução do planejamento do seu desenvolvimento, tendo a referência para a elaboração de Microprojetos de inclusão produtiva, que deverão ser efetivados numa segunda fase, a ser negociada com o novo governo.

Enfim, o curso veio responder à necessidade de espaços institucionais e metodologias adequadas à prática acadêmica do diálogo entre os conhecimentos universais, disciplinares e entre estes e os diversos saberes enraizados na experiência social dos sujeitos do campo. Foram construídos momentos dialógicos de produção de conhecimento que permitiram transitar nas fronteiras entre o conhecimento científico e os saberes sociais emergentes na realidade do campo nordestino.

Essas ações direcionadas para a juventude rural, de geração de renda associando formação cidadã, com base no que diz a agroecologia e, ainda, o estímulo ao intercâmbio de experiências e o acesso a tecnologias fortaleceram as condições necessárias para a elaboração de projetos produtivos, possibilitando a opção dos jovens e das jovens pela inserção e permanência, possibilitando, com isso, a sucessão rural e contribuindo concretamente com o fortalecimento da agricultura camponesa do semiárido cearense. 


\section{Referências bibliográficas}

Furtado, R. \& Furtado, E. (2000). A intervenção participativa dos atores - INPA: uma metodologia de capacitação para o desenvolvimento local sustentável. Brasília: Instituto Interamericano de Cooperação para a Agricultura (IICA).

Furtado, J. S et al. (2014). Projetos produtivos. [Mimeo].

Freire, P. (2014). Política e Educação (1 $1^{\mathrm{a}}$ ed.). São Paulo: Editora Paz e Terra.

Freire, P. (2000). Pedagogia da indignação: cartas pedagógicas e outros escritos. São Paulo: UNESP.

Freire, P. (1987). Pedagogia do Oprimido ( $37^{\mathrm{a}}$ ed.). Rio de Janeiro: Paz e Terra.

Freire, P. (1979). Educacão e mudança (12 ${ }^{\mathrm{a}}$ ed.). Rio de Janeiro: Paz e Terra.

Hawkins, K. \& Price, N. (2000). A Peer Etnographic Tool for social Appraisal and Monitoring of Sexual and Reproductive Health Programs. Swansea: Centre Development Studies, University of Wales.

Universidade de Brasília (2011). Termo de Referência do Curso de Formação Cidadã e Agroecológica para o fortalecimento da Inclusão Produtiva da Juventude Rural. Brasília: UNB.

Universidade da Integração Internacional da Lusofonia Afro-Brasileira (2011). Termo de Referência do curso de formação de jovens rurais para o fortalecimento da agricultura camponesa no semiárido cearense. Fortaleza: UNILAB. 